\title{
WEIGHT MINIMIZATION OF TRUSS STRUCTURES WITH SIZING AND LAYOUT VARIABLES USING INTEGRATED PARTICLE SWARM OPTIMIZER
}

\author{
Ali MORTAZAVI ${ }^{\mathrm{a}}$, Vedat TOĞAN ${ }^{\mathrm{b}}$, Ayhan NUHOĞLU ${ }^{\mathrm{a}}$ \\ ${ }^{a}$ Department of Civil Engineering, Ege University, 35100 Izmir, Turkey \\ ${ }^{b}$ Department of Civil Engineering, Karadeniz Technical University, 61080 Trabzon, Turkey
}

Received 09 Mar 2017; accepted 23 Jun 2017

\begin{abstract}
This study investigates the performances of the integrated particle swarm optimizer (iPSO) algorithm in the layout and sizing optimization of truss structures. The iPSO enhances the standard PSO algorithm employing both the concept of weighted particle and the improved fly-back method to handle optimization constraints. The performance of the recent algorithm is tested on a series of well-known truss structures weight minimization problems including mixed design search spaces (i.e. with both discrete and continuous variables) over various types of constraints (i.e. nodal displacements, element stresses and buckling criterion). The results demonstrate the validity of the proposed approach in dealing with combined layout and size optimization problems.
\end{abstract}

Keywords: particle swarm optimizer, combined sizing/layout optimization, trusses, structural optimization.

\section{Introduction}

In the last decade several new metaheuristic techniques have been developed to solve the structural optimization problems. Genetic algorithms (GA), particle swarm optimization (PSO), harmony search (HS), teaching and learning based optimization (TLBO), firefly algorithm (FA) and flower pollination algorithm (FPA) are a variety of well-established methods for the optimal design of structures. Depending on the optimization purpose, crosssectional areas of the members and/or nodal coordinates separately or simultaneously can be included as the design variables of the problem. Phan et al. (2013), Gholizadeh and Fattahi (2014), Gholizadeh and Poorhoseini (2015), Kaveh and Shokohi (2015), Gholizadeh (2015) and Artar (2016) applied some metaheuristic algorithms for the design optimization problems including the sizing variable only. Although it is possible to obtain better results taking into account both sizing and layout variables, in such a case the optimization problem becomes more complex due to rising number of variables (Hasançebi et al. 2009; Tang et al. 2005; Miguel et al. 2013; Silih et al. 2010; Deb, Gulati 2001; Dede, Ayvaz 2015; Bekdaş et al. 2015; Aydın, Çakır 2015). On the other hand, to acquire practical solutions cross-sectional areas usually should be selected from a predefined discrete list of available structural profiles, while nodal coordinates generally are chosen from a continuous search space. Hence, formulating a mixed variable optimization problem may be unavoidable and employed optimization method should be able to handle both continuous and discrete variables at the same time (Achtziger 2007; Torii et al. 2011).

Dede and Ayvaz (2015) performed sizing and layout optimization of truss structures using teaching learning based optimizer (TLBO). Miguel, L. F. F. and Miguel, L. F. F. (2012) optimized size and layout of truss structures subjected to dynamic constraints using Harmony Search (HS) and Firefly Algorithms (FA). Miguel et al. (2013) represented the efficiency of Firefly Algorithm to optimize size, layout and topology of truss structures. Tang et al. (2005) and Deb and Gulati (2001) carried out sizing and topology optimization of the truss structures using Genetic Algorithm (GA) and its variants.

In this study, an integrated Particle Swarm Optimizer (iPSO) proposed by Mortazavi et al. (2017) is employed for optimal design of 2D and 3D truss structures including both sizing and layout variables to demonstrate its performance on those type problems. The iPSO applies concept of the weighted particle to enhance the search capacity of the standard particle swarm optimizer (PSO). In order to handle the optimization constraints, iPSO implements the improved Fly-back technique. This technique aims to make the role of the weighted particle more prominent and thereby improves the characteristic search aspects (i.e. exploration and exploitation) of the proposed algorithm. 
In order to evaluate the performance of iPSO, several well-known truss structures optimization problems which previously solved in the literature adopting different metaheuristic algorithms, are considered. These problems include various constraints on displacements, stresses and critical buckling loads. Results indicate that iPSO has a good search capability at relatively low computation time to solve combined sizing and layout optimization problems of the truss structures.

The article is structured as follows. The general formulation of truss weight minimization problem is recalled in Section 1. Section 2 briefly describes standard PSO and then presents the proposed iPSO algorithm in detail. Section 3 compares the optimization results with those available in the literature. Section 4 is devoted to discuss about the affirmative features of applying improved Flyback method on the search capability of the iPSO. Conclusions discuss overall performance and strength-points of the iPSO while summarizing the main achievements of this study.

\section{Formulation of truss weight minimization problems}

Since sizing and layout structural optimization problems involve element cross-sectional areas and nodal coordinates as design variables, corresponding constraints and objective function can be expressed as follows:

\section{find $\mathbf{X}$}

Such that:

$\min . \quad W(\mathbf{X})=\sum_{e=1}^{m} L_{e} \rho_{e} A_{e}$

Subjected to

$$
\begin{aligned}
& g_{1}(\mathbf{X})=d_{k}(\mathbf{X}) \leq d_{\max , k} \\
& g_{2}(\mathbf{X})=\sigma_{e}(\mathbf{X}) \leq \sigma_{a, e}(\text { for tension and compression }) \\
& g_{3}(\mathbf{X})=x_{\min , e} \leq x_{e} \leq x_{\max e} \\
& g_{4}(\mathbf{X})=\operatorname{cor}_{\min , p} \leq \operatorname{cor}_{p} \leq \operatorname{cor}_{\max , p}
\end{aligned}
$$

in which $W($.$) is the weight of structure and d_{k}$ and $d_{\text {max, } k}$ are the existing and allowable displacement for node $k$, respectively. The length, material density and crosssectional area of the $e^{\text {th }}$ element are respectively $L_{e}, \rho_{e}$, and $A_{e}$ while $m$ is the total number of elements in the structure. $g_{k}(\mathbf{X})$ is the $k^{\text {th }}$ constraint function, $x_{i}$ is the $i^{\text {th }}$ design variable. Also, $\sigma_{e}$ is the available stress in the $e^{\text {th }}$ element and $\sigma_{a, e}$ is the allowable tension/compression stress for the same element. While, $x_{\min , e}$ and $x_{\max , e}$, are respectively indicate the lower and upper bounds for the cross-sectional area of the eth element; Finally, cor $_{\min , p}$ indicates the lower bounds and $\operatorname{cor}_{\max , p}$ indicates the upper bounds for coordinates of $p^{\text {th }}$ node.

It is notable that, in the structural optimization to achieve a feasible solution the stability of the structure should be sustained during the optimization process. In this respect, several methods based on graph theory and algebraic approaches were provided to check this criterion (Kaveh 2004, 2006). Based on the essence of the problem (e.g complexity level) different approaches individually or in combination can be used (Mortazavi, Toğan 2016).

In the current study to check the stability of the structure evaluation of the condition number of the stiffness matrix is employed. Such that, if the condition number of the stiffness matrix is greater than a predefined large number, system is determined as unstable. This predefined large number (e.g. 1E15) is specified depending on precision defined for complier/interpreter environment that is employed by user to solve optimization problem.

\section{Integrated particle swarm optimization (iPSO)}

Standard Particle Swarm Optimizer (PSO) mimics the behavior of animals (e.g. the colony of fish or swarm of birds) to find food sources or to escape from predators (Kennedy, Eberhart 2001). In the first design cycle of this method, a swarm including several particles is randomly generated while each particle can be a potential solution of the problem. The swarm iteratively flies over the domain of the problem for a unit of time. At the end of the each iteration, each particle finds its own new position. The qualities of these recent positions are evaluated via calculating a proper objective function. In each iteration the best particle in the swarm (global best) is stored in the $\mathbf{X}^{G}$ vector while the best positions previously gained by each particle are stored in the $\mathbf{X}^{P}$ matrix.

Although PSO is applied in the various engineering fields, it is reported that the standard PSO has some drawbacks (e.g. staggering from the convergence in further steps of the process), so different modifications have been applied on the PSO in order to overcome these limitations (Van den Bergh, Engelbrecht 2003; He et al. 2004; Li et al. 2009, 2014).

The iPSO algorithm (Mortazavi, Toğan 2016; Mortazavi et al. 2017) attempts enhancing standard PSO by implementing an improved fly-back method and the concept of weighted particle. The iPSO formulation and its relative terms are shortly described in the following subsections (see more Mortazavi, Toğan 2016; Mortazavi et al. 2017).

\subsection{Weighted particle}

To improve the standard PSO method a unique particle named weighted particle $\left(\mathbf{X}^{W}\right)$ was proposed by Li et al. (2014). Weighted particle is defined as weighted average of all available particles in the swarm. Unlike Li et al. (2014), the effect of it's on the solution process of PSO is examined on the structural optimization problems. The objective value of each particle is taken as weight factor to calculate $\mathbf{X}^{W}$. The weighted particle can hence be defined as:

$$
\mathbf{X}^{W}=\sum_{i=1}^{m} \bar{c}_{i}^{W} \mathbf{X}_{i}^{P},
$$


where $\quad \bar{c}_{i}^{W}=\hat{c}_{i}^{W} / \sum_{i=1}^{m} \bar{c}_{i}^{W}$

and $\quad \hat{c}_{i}^{W}=\frac{\max _{1 \leq k \leq m}\left(f\left(\mathbf{X}_{k}^{P}\right)\right)-f\left(\mathbf{X}_{i}^{P}\right)+\varepsilon}{\max _{1 \leq k \leq m}\left(f\left(\mathbf{X}_{k}^{P}\right)\right)-\min _{1 \leq k \leq m}\left(f\left(\mathbf{X}_{k}^{P}\right)\right)+\varepsilon}$.

In Eqns (2)-(3), $m$ is the number of particles, $\mathbf{X}^{W}$ is the position vector of the weighted particle, $\mathbf{X}_{i}^{P}$ is $i^{\text {th }}$ particle stored in the $\mathbf{X}^{P}, f($.) returns the corresponding value of the objective function of the optimization problem, also $\max ($.$) and \min ($.$) , respectively, are the worst and best ob-$ jective function values of the particles available in the $\mathbf{X}^{P}$ matrix. Also $\varepsilon$ is a small positive value to prevent division by zero condition which in this study is taken as 0.001 .

\subsection{Improved fly-back mechanism}

To handle the constraints of the optimization problems, the proposed fly-back mechanism (He et al. 2004) is improved to increase the convergence rate of the algorithm and the guidance role of the weighted particle. And it is donated as improved fly-back technique. The following scheme is employed to use the improved fly-back technique. First, problem constraints are divided in two groups: (i) numerical constraints, those do not entail structural analysis to evaluate constraint(s) violation, e.g. side constraints on cross-sectional areas or nodal coordinates; (ii) Characteristic constraints, those who entail structural analysis to determine their violation, e.g. existing stresses and displacements. Next, if a particle violates the numerical constraint(s), the corresponding violated components in the particle are replaced with the same components stored in the weighted particle. The new particle is evaluated and if it gives a better objective value it replaces the old one and if not, it is reset to its previous best position stored in the $\mathbf{X}^{P}$.

\subsection{Formulation of the iPSO algorithm}

iPSO utilizes the weighted particle $\left(\mathbf{X}^{W}\right)$ not only to overcome reducing or vanishing the guidance effect of particle own prior best position $X_{i}^{P}$ and position of the best particle in the swarm $\left(\mathbf{X}^{G}\right)$ when a particle is located very close to one or even both of these landmark points but also to involve all particles' experience through weighted particle in the position updating of each particle. Consequently, iPSO is formulated as below:

$$
\begin{array}{r}
{ }^{t+1} \mathbf{V}_{i}=\varphi_{4 i}\left({ }^{t} \mathbf{X}^{W}-{ }^{t} \mathbf{X}_{i}\right) \quad i \geq 1, \quad \varphi_{4 i}=C_{4} \times \operatorname{rand}_{4 i} \\
\text { if } \operatorname{rand}_{0 i} \leq \alpha ; \\
{ }^{t+1} \mathbf{V}_{i}=w_{i} \times{ }^{t} \mathbf{V}_{i}+\left(\varphi_{1 i}+\varphi_{2 i}+\varphi_{3 i}\right)\left({ }^{t} \mathbf{X}_{j}^{P}-{ }^{t} \mathbf{X}_{i}\right)+ \\
\varphi_{2 i}\left({ }^{t} \mathbf{X}^{G}-{ }^{t} \mathbf{X}_{j}^{P}\right)+\varphi_{3 i}\left({ }^{t} \mathbf{X}^{W}-{ }^{t} \mathbf{X}_{j}^{P}\right) \\
\text { if } \operatorname{rand}_{0 i}>\alpha ;
\end{array}
$$

$$
\begin{array}{r}
{ }^{t+1} \mathbf{X}_{i}={ }^{t} \mathbf{X}_{i}+{ }^{t+1} \mathbf{V}_{i} \quad i \geq 1, \quad j \leq m, \quad \varphi_{1 i}=C_{1} \times \operatorname{rand}_{1 i} \\
\varphi_{2 i}=C_{2} \times \operatorname{rand}_{2 i}, \quad \varphi_{3 i}=C_{3} \times \operatorname{rand}_{3 i} .
\end{array}
$$

In Eqns (4)-(6), superscripts of " $t$ " and " $t+1$ " denote current step and next step, respectively. So, ${ }^{t+1} \mathbf{V}_{i}$ is the updated velocity, $w_{i}$ is the inertia term of current velocity, and ${ }^{t} \mathbf{V}_{i}$ is the current velocity of $i^{\text {th }}$ particle. $C_{1}, C_{2}$, $C_{3}$, and $C_{4}$ are acceleration factors, where respectively can

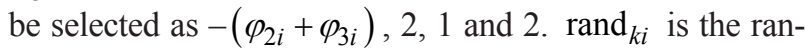
dom number selected from the $[0,1]$ interval, in which $k \in\{0,1,2,3,4\}$. Also, ${ }^{t} \mathbf{X}_{j}^{P}$ indicates the randomly selected particle from the current matrix of $\mathbf{X}^{P}$. Moreover, ${ }^{t} \mathbf{X}^{G}$ is the global best particle up to current step while ${ }^{t+1} \mathbf{X}_{i}$ and ${ }^{t} \mathbf{X}_{i}$, respectively, represent the updated position and current position of the $i^{\text {th }}$ particle. The weighted particle calculated for the current step is shown by ${ }^{t} \mathbf{X}^{W}$. In each iteration, $w_{i}$ is randomly selected from $[0.5,0.55]$ and $\alpha=0.4$. Li et al. (2014) established these parameters adjustments for scalar functions with continuous search spaces.

Since discrete variables are also adopted in this study, Eqns (2)-(5) are modified as follows:

$$
\mathbf{X}^{W}=\operatorname{INT}\left(\sum_{i=1}^{m} c_{i} \mathbf{X}_{i}^{P}\right)
$$

$$
{ }^{t+1} \mathbf{X}_{i}=\operatorname{INT}\left({ }^{t} \mathbf{X}_{i}+\varphi_{4 i}\left({ }^{t} \mathbf{X}^{W}-{ }^{t} \mathbf{X}_{i}\right)\right) \text { if } \operatorname{rand}_{0 i} \leq \alpha
$$

if $\operatorname{rand}_{0 i}>\alpha$

$$
{ }^{t+1} \mathbf{X}_{i}=I N T\left(\begin{array}{l}
{ }^{t} \mathbf{X}_{i}+w_{i} \times{ }^{t} \mathbf{V}_{i}+\left(\varphi_{1 i}+\varphi_{2 i}+\varphi_{3 i}\right)\left({ }^{t} \mathbf{X}_{j}^{P}-{ }^{t} \mathbf{X}_{i}\right)+ \\
\varphi_{2 i}\left({ }^{t} \mathbf{X}^{G}-{ }^{t} \mathbf{X}_{j}^{P}\right)+\varphi_{3 i}\left({ }^{t} \mathbf{X}^{W}-{ }^{t} \mathbf{X}_{j}^{P}\right)
\end{array}\right) \text { (9) }
$$

The operator INT (.) in above formulations takes the integer part of any scalar variable. The rest of the definitions are the same as for Eqns (2)-(5). As can be seen from given formulation the $\mathbf{X}^{W}$ plays significant role in the guidance of swarm. In the proposed method the weighted particle accompanied with $\mathbf{X}^{W}$ form the particular motion orientation for other particles. So, excepted particles own experiences stored in $\mathbf{X}^{P}$ each particle has two reasonable guidance points (i.e. $\mathbf{X}^{W}$ and $\mathbf{X}^{G}$ ), in comparison to standard PSO where $\mathbf{X}^{G}$ takes over this role individually.

It is remarkable that, the weighted particle includes the data stored in all particles while associates them related with their objective values (i.e. for a minimization problem, particle with lower objective value has a higher impact). Neglecting particles inertia, in each iteration $\mathbf{X}^{W}$ spots a location in search domain based on combination of detected locations by swarm up to current step. So, this particle (as gravity center of colony) lies closer to better particles. Subsequently, since it cannot stand so far away from swarm it generally provides a local search, and moving toward this particle increases the exploitation ability of the algorithm. On the other hand, similar to the standard PSO, holding the effect of particles' inertia, moving toward the $\mathbf{X}_{i}^{P}$ and $\mathbf{X}^{G}$ (for $\operatorname{rand}_{0 i}>\alpha$ ) 
provides exploration ability of the algorithm. However, to reach the global optimum through the search space, a balance between exploration and exploitation is required (Gholizadeh 2013). In iPSO, this balance is provided via adjusting attraction factor $(\alpha)$.

\subsection{Parameters of iPSO}

To exhibit the effect of variation of attraction factor $(\alpha)$ and initial velocity inertia term $(w)$ on iPSO algorithm performance, sensitivity analysis based on the graphical sensitivity method described in Lee et al. (2013) was carried out. These analyses provide illustrative data about the effect of adjustable parameters, i.e. changing a parameter either has a positive or negative effect on the performance of the algorithm. The corresponding mapped ranges for the attraction factor $(\alpha)$, initial velocity inertia term $(w)$, and number of population $(N)$ are illustrated in Figure 1. Results of the sensitivity analysis performed for 18-bar and 39-bar trusses verify the results obtained by Li et al. (2014) and Mortazavi and Toğan (2017). According to these results, the best combination of internal parameters ( $\alpha$ and $w$ ) are $w=[0.5,0.55]$ and $\alpha=0.4$, respectively. As a consequence, considering the numerical experiments conducted in the current study, it can be worth to say that the appropriate values for $\alpha$ and $w$ are 0.4 and 0.5 for the examples to be investigated in the present study.

\section{Design examples}

Five benchmark truss optimization problems are solved to evaluate the performance of the iPSO. Due to the stochas-

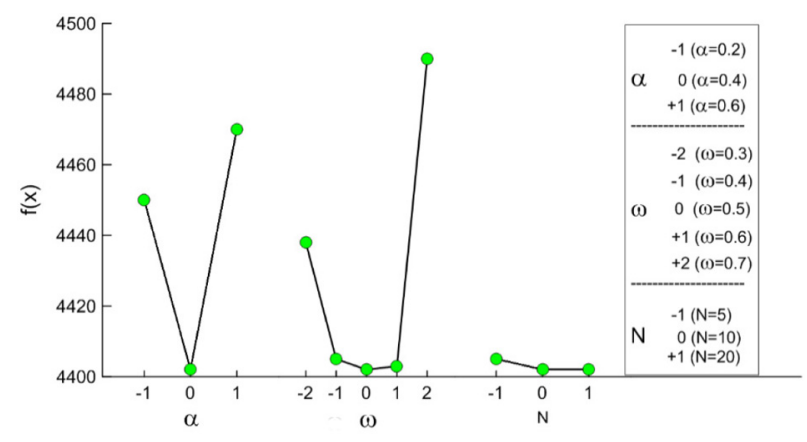

a. 18-bar truss

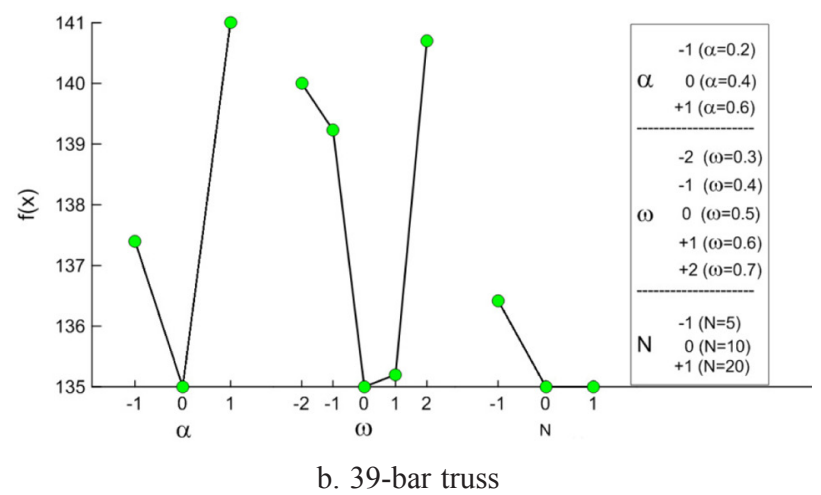

Fig. 1. Illustrative results of the sensitivity analysis for the internal parameters of iPSO algorithm

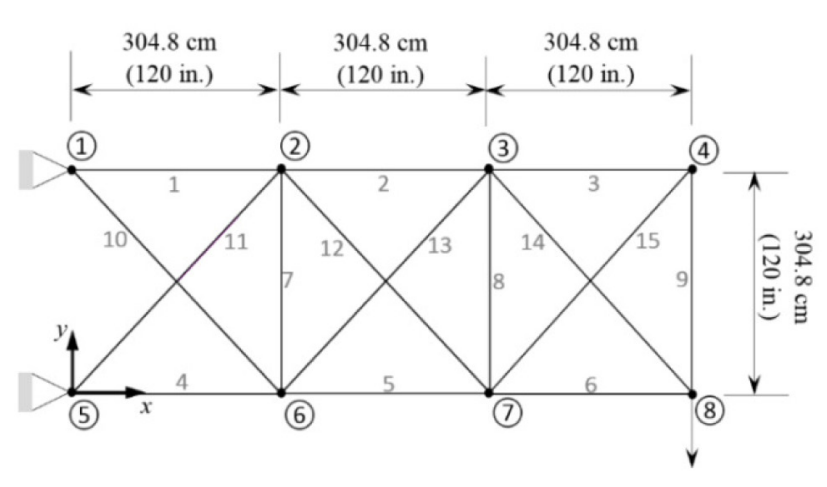

Fig. 2. Schematic of the planar 15-bar truss structure

tic nature of the optimization technique, 30 independent runs are carried out for solving each test problem. For more clarity the statistical information and number of objective function evaluation (OFEs) about each solution also are provided. It is notable that some statistical data and OFEs of referred studies are not reported in the relative literature.

\subsection{5-bar planar truss structure}

As shown in Figure 2, the 2D 15-bar truss structure is taken as the first test case. The design parameters adopted in this example are presented in Table 1. Population size and allowable number of iterations are respectively set as 20 and 300 for this example.

Table 2 compares the optimum design obtained by the iPSO with those using other techniques available in relative studies. In addition Table 2 presents the statistical information about this problem, as well. According to data tabulated in Table 2, iPSO found the lightest solution among the reported results by $\mathrm{Wu}$ and Chow (1995) using GA, Tang et al. (2005) using improved GA, Hwang and He (2006) applying ARSAGA, Rahami et al. (2008) using Force method and GA, Dede and Ayvaz (2015) using TLBO, and Miguel et al. (2013) using FA. However, the lightest design for this example was reported by Gholizadeh (2013) using SCPSO. This result, $72.5413 \mathrm{lb}$, is only $\% 0.3 \mathrm{lb}$ smaller than the design obtained by using iPSO. The acquired optimized structure is shown in Figure 3 . The best weight is achieved at $249^{\text {th }}$ iteration (i.e. after 4980 structural analyses) and it remains unchanged until the last iteration is reached. The standard deviation for the 30 independent runs is $2.023 \mathrm{lb}$ and it indicates that dispersion of the outcomes is in the acceptable range from mean value of the solutions. Based on the comparisons made in Table 2, it can be expressed that iPSO has adequate capability to handle the layout and sizing
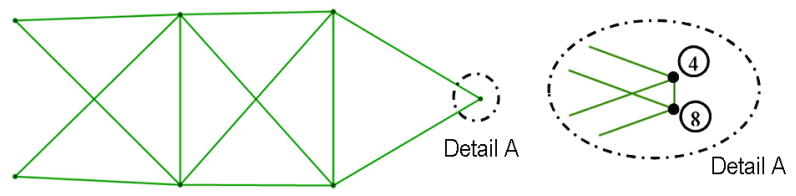

Fig. 3. Optimal layout for the planar 15-bar truss problem 
Table 1. Input data for the planar 15-bar truss problem

\begin{tabular}{|c|c|}
\hline & Material properties \\
\hline Young's modulus & $E=68947.5728 \mathrm{MPa}(10 \mathrm{Msi})$ \\
\hline Density & $\rho=27.1447 \mathrm{kN} / \mathrm{m}^{3}\left(0.1 \mathrm{lb} / \mathrm{in}^{3}\right)$ \\
\hline \multirow[t]{2}{*}{ Allowable stress } & $\pm 172.36898 \mathrm{MPa}( \pm 25 \mathrm{ksi})$ \\
\hline & Design variables \\
\hline Sizing variables & $A_{i}=1,2, \ldots, 15$ \\
\hline \multirow[t]{9}{*}{ Discrete area set, $S$} & $\begin{array}{c}S=\{0.111,0.141,0.174,0.220,0.270,0.287,0.347,0.440,0.539 \\
0.954,1.081,1.174,1.333,1.488,1.764,2.142,2.697,2.800 \\
3.131,3.565,3.813,4.805,5.952,6.572,7.192,8.525,9.300 \\
10.850,13.330,14.290,17.170,19.180\} \text { in }^{2}\end{array}$ \\
\hline & Layout variables \\
\hline & $254 \mathrm{~cm}(100 \mathrm{in}) \leq X_{2}=X_{6} \leq 355.6 \mathrm{~cm}(140 \mathrm{in})$ \\
\hline & $558.8 \mathrm{~cm}(220 \mathrm{in}) \leq X_{3}=X_{7} \leq 660.4 \mathrm{~cm}(260 \mathrm{in})$ \\
\hline & $254 \mathrm{~cm}(100 \mathrm{in}) \leq \mathrm{Y}_{2}, \mathrm{Y}_{3} \leq 355.6 \mathrm{~cm}(140 \mathrm{in})$ \\
\hline & $127 \mathrm{~cm}(50 \mathrm{in}) \leq \mathrm{Y}_{4} \leq 228.6 \mathrm{~cm}(90 \mathrm{in})$ \\
\hline & $-50.8 \mathrm{~cm}(-20 \mathrm{in}) \leq \mathrm{Y}_{6}, \mathrm{Y}_{7} \leq 50.8 \mathrm{~cm}(20 \mathrm{in})$ \\
\hline & $50.8 \mathrm{~cm}(20 \mathrm{in}) \leq \mathrm{Y}_{8} \leq 152.4 \mathrm{~cm}(60 \mathrm{in})$ \\
\hline & Nodal loads \\
\hline Node number & $\mathrm{x}$ \\
\hline \multirow[t]{2}{*}{8} & $-44.537 \mathrm{kN}(-10 \mathrm{kips})$ \\
\hline & Constraints \\
\hline Displacement & - \\
\hline Euler buckling & - \\
\hline Stress & $\sigma_{\mathrm{e}} \leq$ allowable stress \\
\hline
\end{tabular}

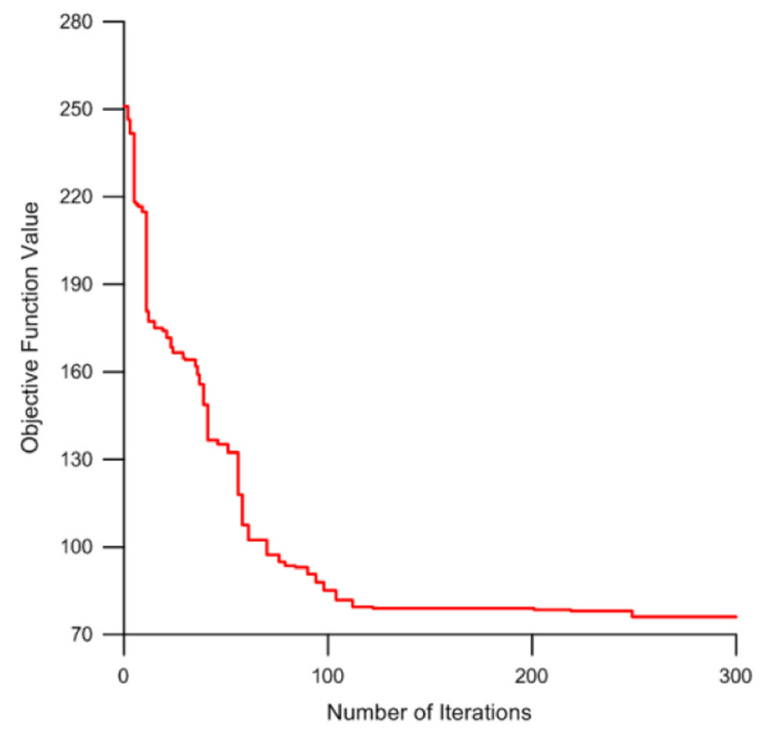

Fig. 4. Convergence history for the planar 15-bar truss using iPSO

optimization problem. Figure 4 shows the convergence history of the 15-bar truss structure for iPSO.

\subsection{8-bar planar truss structure}

The 18 bar truss shown in Figure 5 is selected as the second example of the combined sizing/layout optimization.
Input data required for this test case are listed in Table 3. The population size and allowable number of iterations are respectively set as 10 and 500 for this example.

The optimized layout of the structure is shown in Figure 6. The optimum design found by the iPSO is compared with those reported in the relative literature in Table 4. According to the provided information in Table 4, iPSO finds the lightest solution in comparison with the results found by Hasançebi and Erbatur (2002) using SA, Kaveh and Kalatjari (2004) using Force method and GA, Rahami et al. (2008) using Force method and GA, Lee and Geem (2005) using HS, and also Dede and Ayvaz (2015) using TLBO. However, comparing the designs presented in Table 4 it is notable that the better result among them is the one obtained by Gholizadeh (2013) employing SCPSO. The optimum design is reached at $445^{\text {th }}$ iteration (i.e. after 4450 structural analyses) and any improvement in the solution is not obtained until reaching to the maximum allowable number of iterations. The statistical data for current example is also provided in Table 4. The data shows that the value of the standard deviation is equal to $14.899 \mathrm{lb}$ for the set of obtained solutions through 30 independent runs. This value indicates that distribution of the obtained results over their mean value is statistically admissible. The corresponding convergence history of the 18-bar truss structure for iPSO is demonstrated in Figure 7. 
Table 2. Comparison of the iPSO optimization results with the literature for the 15-bar truss problem

\begin{tabular}{|c|c|c|c|c|c|c|c|c|}
\hline Design variables & $\begin{array}{l}\text { Wu and } \\
\text { Chow } \\
(1995) \\
\text { GA }\end{array}$ & $\begin{array}{l}\text { Tang } \\
\text { et al. } \\
(2005) \\
\text { iGA }\end{array}$ & $\begin{array}{c}\text { Hwang } \\
\text { and He } \\
(2006) \\
\text { ARSAGA }\end{array}$ & $\begin{array}{l}\text { Rahami } \\
\text { et al. } \\
\text { (2008) } \\
\text { GA }\end{array}$ & $\begin{array}{l}\text { Miguel } \\
\text { et al. } \\
(2013) \\
\text { FA }\end{array}$ & $\begin{array}{c}\text { Gholizadeh } \\
\text { (2013) } \\
\text { SCPSO }\end{array}$ & $\begin{array}{c}\text { Dede and } \\
\text { Ayvaz }(2015) \\
\text { TLBO }\end{array}$ & $\begin{array}{l}\text { This } \\
\text { study } \\
\text { iPSO }\end{array}$ \\
\hline \multicolumn{9}{|c|}{ Sizing variables $\left(\mathrm{in}^{2}\right)$} \\
\hline$A_{1}$ & 1.174 & 1.081 & 0.954 & 1.081 & 0.954 & 0.954 & 1.081 & 1.081 \\
\hline$A_{2}$ & 0.954 & 0.539 & 1.081 & 0.539 & 0.539 & 0.539 & 0.954 & 0.539 \\
\hline$A_{3}$ & 0.44 & 0.287 & 0.44 & 0.287 & 0.22 & 0.270 & 0.141 & 0.27 \\
\hline$A_{4}$ & 1.333 & 0.954 & 1.174 & 0.954 & 0.954 & 0.954 & 1.081 & 0.954 \\
\hline$A_{5}$ & 0.954 & 0.954 & 1.488 & 0.539 & 0.539 & 0.539 & 0.539 & 0.539 \\
\hline$A_{6}$ & 0.174 & 0.22 & 0.27 & 0.141 & 0.22 & 0.174 & 0.347 & 0.141 \\
\hline$A_{7}$ & 0.44 & 0.111 & 0.27 & 0.111 & 0.111 & 0.111 & 0.111 & 0.111 \\
\hline$A_{8}$ & 0.44 & 0.111 & 0.347 & 0.111 & 0.111 & 0.111 & 0.174 & 0.111 \\
\hline$A_{9}$ & 1.081 & 0.287 & 0.22 & 0.539 & 0.287 & 0.287 & 0.141 & 0.27 \\
\hline$A_{10}$ & 1.333 & 0.22 & 0.44 & 0.44 & 0.44 & 0.347 & 0.27 & 0.287 \\
\hline$A_{11}$ & 0.174 & 0.44 & 0.22 & 0.539 & 0.44 & 0.347 & 0.22 & 0.44 \\
\hline$A_{12}$ & 0.174 & 0.44 & 0.44 & 0.27 & 0.22 & 0.220 & 0.141 & 0.27 \\
\hline$A_{13}$ & 0.347 & 0.111 & 0.347 & 0.22 & 0.22 & 0.220 & 0.44 & 0.287 \\
\hline$A_{14}$ & 0.347 & 0.22 & 0.27 & 0.141 & 0.27 & 0.174 & 0.347 & 0.174 \\
\hline$A_{15}$ & 0.44 & 0.347 & 0.22 & 0.287 & 0.22 & 0.270 & 0.141 & 0.27 \\
\hline \multicolumn{9}{|c|}{ Layout variables (in) } \\
\hline$X_{2}$ & 123.189 & 133.612 & 118.346 & 101.5775 & 114.967 & 137.2216 & 100.0042 & 132.2415 \\
\hline$X_{3}$ & 231.595 & 234.752 & 225.209 & 227.9112 & 247.04 & 259.9093 & 241.0473 & 257.4379 \\
\hline$Y_{2}$ & 107.189 & 100.449 & 119.046 & 134.7986 & 125.919 & 123.5006 & 118.8228 & 128.3136 \\
\hline$Y_{3}$ & 119.175 & 104.738 & 105.086 & 128.2206 & 111.067 & 110.0020 & 100.0829 & 111.2506 \\
\hline$Y_{4}$ & 60.462 & 73.762 & 63.375 & 54.863 & 58.298 & 59.9356 & 50 & 59.9894 \\
\hline$Y_{6}$ & 16.728 & -10.067 & -20 & -16.4484 & -17.564 & -5.1799 & 3.1411 & -10.5543 \\
\hline$Y_{7}$ & 15.565 & -1.339 & -20 & -16.4484 & -5.821 & 4.2193 & -9.6997 & 10.7686 \\
\hline$Y_{8}$ & 36.645 & 50.402 & 57.722 & 54.8572 & 31.465 & 57.8829 & 46.8963 & 60.0 \\
\hline \multicolumn{9}{|c|}{ Statistical results } \\
\hline Best weight (lb) & 120.52 & 79.82 & 104.573 & 76.6854 & 75.55 & 72.5143 & 76.6519 & 72.7373 \\
\hline Worst weight (lb) & & & & & & 80.156 & & 76.522 \\
\hline Mean weight (lb) & & & & & & 76.411 & & 74.316 \\
\hline Std. deviation (lb) & & & & & & 1.922 & & 2.023 \\
\hline OFEs & 6000 & 8000 & 16000 & 8000 & 8000 & 4500 & 16000 & 4980 \\
\hline
\end{tabular}

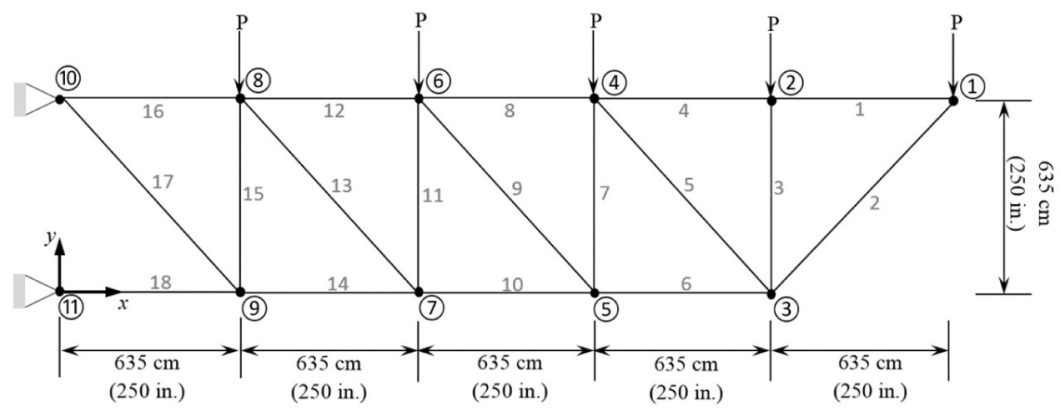

Fig. 5. Schematic of the planar 18-bar truss structure 
Table 3. Input data for the planar 18-bar truss problem

\begin{tabular}{|c|c|}
\hline & Material properties \\
\hline Young's modulus & $E=68947.5728 \mathrm{MPa}(10 \mathrm{Msi})$ \\
\hline Density & $\rho=2768 \mathrm{~kg} / \mathrm{m}^{3}\left(0.1 \mathrm{lb} / \mathrm{in}^{3}\right)$ \\
\hline \multirow[t]{2}{*}{ Allowable stress } & $\pm 137.8951 \mathrm{MPa}( \pm 20 \mathrm{ksi})$ \\
\hline & Design variables \\
\hline Sizing variables & Members \\
\hline$A_{1}$ & $1,4,8,12,16$ \\
\hline$A_{2}$ & $2,6,10,14,18$ \\
\hline$A_{3}$ & $3,7,11,15$ \\
\hline$A_{4}$ & $5,9,13,17$ \\
\hline \multirow[t]{8}{*}{ Discrete area set } & $\{2.0,2.25, \ldots, 21.5,21.75\} \mathrm{in}^{2}$ \\
\hline & Layout variables \\
\hline & $-571.5 \mathrm{~cm}(-225 \mathrm{in}) \leq \mathrm{Y}_{3}, \mathrm{Y}_{5}, \mathrm{Y}_{7}, \mathrm{Y}_{9} \leq 622.3 \mathrm{~cm}(245 \mathrm{in})$ \\
\hline & $1968.5 \mathrm{~cm}(775 \mathrm{in}) \leq X_{3} \leq 3111.5 \mathrm{~cm}(1225 \mathrm{in})$ \\
\hline & $1333.5 \mathrm{~cm}(525 \mathrm{in}) \leq \mathrm{X}_{5} \leq 2349.5 \mathrm{~cm}(925 \mathrm{in})$ \\
\hline & $698.5 \mathrm{~cm}(275 \mathrm{in}) \leq X_{7} \leq 1841.5 \mathrm{~cm}(725 \mathrm{in})$ \\
\hline & $63.5 \mathrm{~cm}(25 \mathrm{in}) \leq X_{9} \leq 1206.5 \mathrm{~cm}(475 \mathrm{in})$ \\
\hline & Loading conditions \\
\hline Node number & $\mathrm{x}$ \\
\hline 1 & $-44.537 \mathrm{kN}(-10 \mathrm{kips})$ \\
\hline 2 & $-44.537 \mathrm{kN}(-10 \mathrm{kips})$ \\
\hline 4 & $-44.537 \mathrm{kN}(-10 \mathrm{kips})$ \\
\hline 6 & $-44.537 \mathrm{kN}(-10 \mathrm{kips})$ \\
\hline \multirow[t]{2}{*}{8} & $-44.537 \mathrm{kN}(-10 \mathrm{kips})$ \\
\hline & Constraints \\
\hline Displacement & - \\
\hline Euler buckling & $\sigma_{e b} \leq \frac{\alpha E A_{e}}{L_{e}^{2}}$ \\
\hline Stress & $\sigma_{\mathrm{e}} \leq$ allowable stress \\
\hline
\end{tabular}

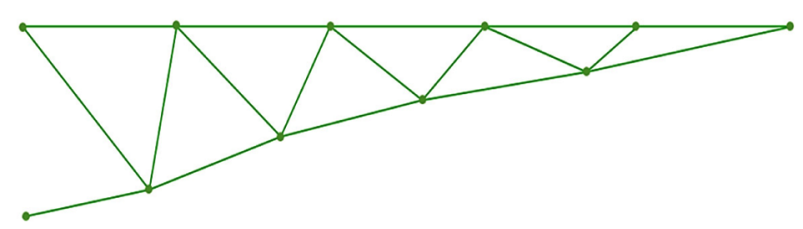

Fig. 6. Optimal layout for the planar 18-bar truss problem

\subsection{5-bar space truss tower}

The third example deals with the combined sizing/layout optimization of the 3D 25-bar truss tower shown in Figure 8. Problem specifications are listed in Table 5. Initial values of nodal coordinates and members grouping are presented in Table 6 . The symmetry of structure is maintained during the optimization process. The population size and allowable number of iterations are set as 10 and 500 , respectively.

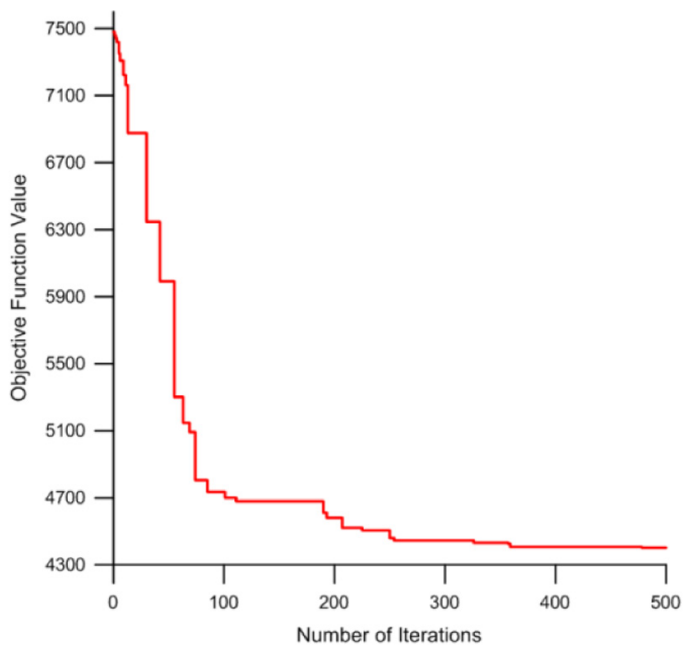

Fig. 7. Convergence history for the planar 18-bar truss using iPSO 
Table 4. Comparison of the iPSO optimization results with the literature for the planar 18-bar truss problem

\begin{tabular}{|c|c|c|c|c|c|c|c|}
\hline Design variables & $\begin{array}{l}\text { Hasançebi } \\
\text { and Erbatur } \\
\text { (2002) SA }\end{array}$ & $\begin{array}{c}\text { Kaveh and } \\
\text { Kalatjari } \\
\text { (2004) GA }\end{array}$ & $\begin{array}{c}\text { Rahami } \\
\text { et al. }(2008) \\
\text { GA }\end{array}$ & $\begin{array}{c}\text { Lee and } \\
\text { Geem } \\
(2005)\end{array}$ & $\begin{array}{c}\text { Gholizadeh } \\
(2013) \\
\text { SCPSO }\end{array}$ & $\begin{array}{c}\text { Dede and } \\
\text { Ayvaz (2015) } \\
\text { TLBO }\end{array}$ & $\begin{array}{c}\text { This study } \\
\text { iPSO }\end{array}$ \\
\hline \multicolumn{8}{|c|}{ Sizing variables $\left(\mathrm{in}^{2}\right)$} \\
\hline$A_{1}$ & 12.25 & 12.25 & 12.75 & 12.62 & 12.50 & 12.25 & 14.25 \\
\hline$A_{2}$ & 17.5 & 18 & 18.5 & 17.22 & 17.50 & 17.5 & 11.75 \\
\hline$A_{3}$ & 5.75 & 5.25 & 4.75 & 6.17 & 5.75 & 5.75 & 6.00 \\
\hline$A_{4}$ & 4.25 & 4.25 & 3.25 & 3.55 & 3.75 & 4.25 & 8.00 \\
\hline \multicolumn{8}{|c|}{ Layout variables (in) } \\
\hline$X_{3}$ & 910 & 913 & 917.4475 & 903.1 & 907.2491 & 906.9373 & 916.4975 \\
\hline$Y_{3}$ & 179 & 186.8 & 193.7899 & 174.3 & 179.8671 & 179.8866 & 190.5241 \\
\hline$X_{5}$ & 638 & 650 & 654.3243 & 630.3 & 636.7873 & 637.0087 & 916.4975 \\
\hline$Y_{5}$ & 141 & 150.5 & 159.9436 & 136.3 & 141.8271 & 142.617 & 152.9217 \\
\hline$X_{7}$ & 408 & 418.8 & 424.4821 & 402.1 & 407.9442 & 408.6414 & 649.4695 \\
\hline$Y_{7}$ & 91 & 97.4 & 108.5779 & 90.5 & 94.0559 & 94.1563 & 105.425 \\
\hline$X_{9}$ & 198 & 204.8 & 208.4691 & 195.3 & 198.7897 & 199.6503 & 205.4255 \\
\hline$Y_{9}$ & 24 & 26.7 & 37.6349 & 30.6 & 29.5157 & 25.3657 & 36.4252 \\
\hline \multicolumn{8}{|c|}{ Statistical results } \\
\hline Best weight (lb) & 4533.24 & 4547.9 & 4530.7 & 4525.6 & 4512.365 & 4528.797 & 4520.99 \\
\hline Worst weight (lb) & & & & & 4621.227 & & 4560.27 \\
\hline Mean weight (lb) & & & & & 4551.709 & & 4526.585 \\
\hline Std. deviation (lb) & & & & & 37.691 & & 14.889 \\
\hline OFEs & - & 5000 & 8000 & 25000 & 4500 & 16000 & 4450 \\
\hline
\end{tabular}

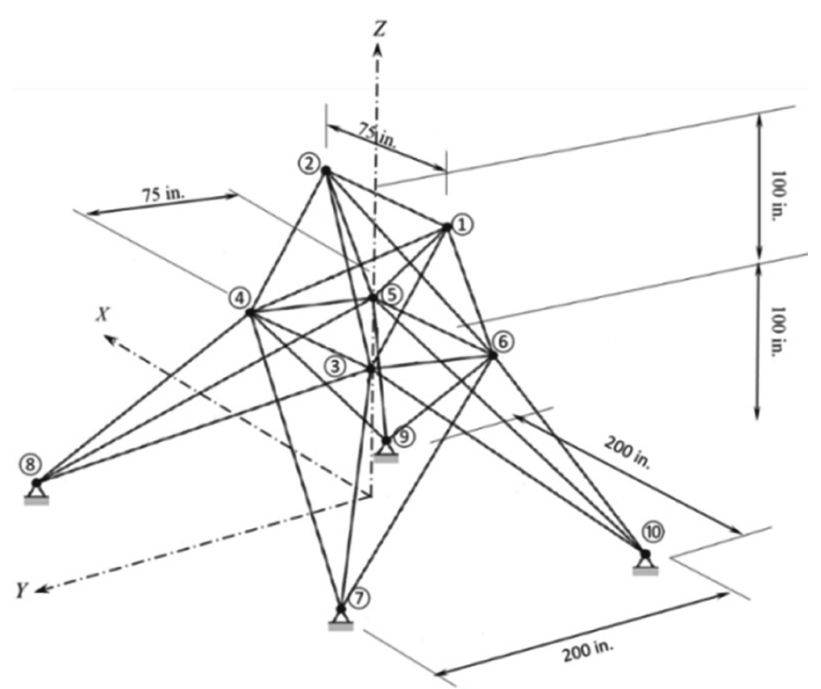

Fig. 8. Schematic of the spatial 25-bar truss tower

The optimum design is compared with those available in the relative literature in Table 7. The iPSO finds the lightest solution for the current structure in comparison with the reported results by $\mathrm{Wu}$ and Chow (1995), Tang et al. (2005) using different variants of GA, Rahami et al. (2008), Kaveh and Kalatjari (2004) using Force method and GA. The results show that iPSO and SCPSO

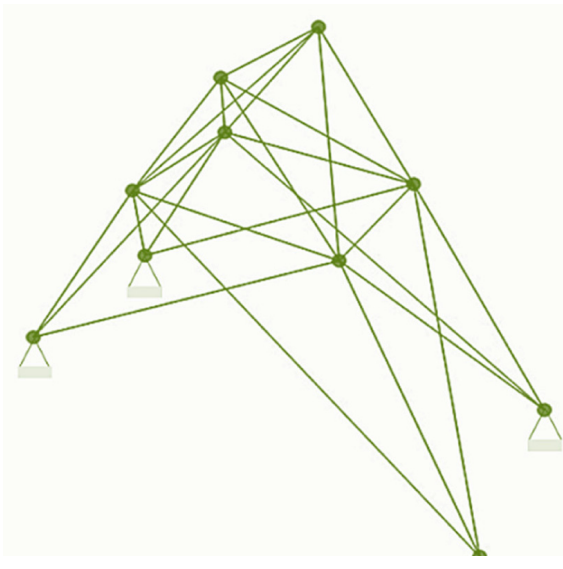

Fig. 9. Optimal layout for the spatial 25-bar truss problem

(Gholizadeh 2013) converge to better solution in comparison with others however there is a negligible difference between these designs in the point view of engineering. The optimal layout found for this problem is shown in Figure 9. It is accomplished at $487^{\text {th }}$ generation (i.e. after 4870 structural analyses) to find the optimum design reported in Table 7. Any further enhancement in the design is not attained until the maximum iteration number is reached. The graphical representation of this process is illustrated in Figure 10. The statistical data for this exam- 
Table 5. Input data for the spatial 25-bar truss problem

\begin{tabular}{|c|c|c|c|}
\hline \multicolumn{4}{|c|}{ Material properties } \\
\hline Young's mo & & \multicolumn{2}{|c|}{$E=68947.5728 \mathrm{MPa}(10 \mathrm{Msi})$} \\
\hline Density & \multicolumn{3}{|c|}{$\rho=2768 \mathrm{~kg} / \mathrm{m}^{3}\left(0.1 \mathrm{lb} / \mathrm{in}^{3}\right)$} \\
\hline Allowable s & \multicolumn{3}{|c|}{ $\pm 275.80 \mathrm{MPa}( \pm 40 \mathrm{ksi})$} \\
\hline \multicolumn{4}{|c|}{ Design variables } \\
\hline Sizing varia & \multicolumn{3}{|c|}{$A_{i}=1,2, \ldots, 8$} \\
\hline $\begin{array}{l}\text { Nodal coord } \\
\text { metry condi }\end{array}$ & \multicolumn{3}{|c|}{$\begin{array}{c}\mathrm{x}_{4}=\mathrm{x}_{5}=-\mathrm{x}_{3}=-\mathrm{x}_{6} ; \mathrm{x}_{8}=\mathrm{x}_{9}=-\mathrm{x}_{7}=-\mathrm{x}_{10} ; \mathrm{y}_{3}=\mathrm{y}_{4}=-\mathrm{y}_{5}=-\mathrm{y}_{6} \\
\mathrm{y}_{7}=\mathrm{y}_{8}=-\mathrm{y}_{9}=-\mathrm{y}_{10} ; \mathrm{z}_{3}=\mathrm{z}_{4}=\mathrm{z}_{5}=\mathrm{z}_{6}\end{array}$} \\
\hline Discrete are & \multicolumn{3}{|c|}{$0.1,0.2, \ldots, 2.6,2.8,3.0,3.2,3.4$} $\mathrm{in}^{2}$ \\
\hline \multicolumn{4}{|c|}{ Layout variables } \\
\hline \multicolumn{4}{|c|}{$50.8 \mathrm{~cm}(20$ in $) \leq X_{4} \leq 152.4 \mathrm{~cm}(60$ in $)$} \\
\hline \multicolumn{4}{|c|}{$101.6 \mathrm{~cm}(40$ in $) \leq X_{8} \leq 203.2 \mathrm{~cm}(80 \mathrm{in})$} \\
\hline \multicolumn{4}{|c|}{$101.6 \mathrm{~cm}(40 \mathrm{in}) \leq Y_{4} \leq 203.2 \mathrm{~cm}(80 \mathrm{in})$} \\
\hline \multicolumn{4}{|c|}{$254 \mathrm{~cm}(100 \mathrm{in}) \leq \mathrm{Y}_{8} \leq 355.6 \mathrm{~cm}$ (140 in $)$} \\
\hline \multicolumn{4}{|c|}{$228.6 \mathrm{~cm}(90 \mathrm{in}) \leq Z_{4} \leq 330.2 \mathrm{~cm}(130 \mathrm{in})$} \\
\hline \multicolumn{4}{|c|}{ Loading conditions } \\
\hline $\begin{array}{l}\text { Node num- } \\
\text { ber }\end{array}$ & $\mathrm{x}$ & $\mathrm{y}$ & $\mathrm{z}$ \\
\hline 1 & $4.454 \mathrm{kN}(-1.0 \mathrm{kips})$ & $-44.537 \mathrm{kN}(-10 \mathrm{kips})$ & $-44.537 \mathrm{kN}(-10 \mathrm{kips})$ \\
\hline 2 & 0 & $-44.537 \mathrm{kN}(-10 \mathrm{kips})$ & $-44.537 \mathrm{kN}$ ( $-10 \mathrm{kips})$ \\
\hline 3 & $2.227 \mathrm{kN}$ (0.5 kips) & 0 & 0 \\
\hline 6 & $2.672 \mathrm{kN}$ (0.6 kips) & 0 & 0 \\
\hline \multicolumn{4}{|c|}{ Constraints } \\
\hline Displacemer & \multicolumn{3}{|c|}{$\left|\Delta_{\mathrm{i}}\right| \leq 0.89 \mathrm{~cm}(0.35 \mathrm{in}) ; i=1, \ldots, 6$} \\
\hline Euler buckli & \multicolumn{3}{|c|}{-} \\
\hline Stress & \multicolumn{3}{|c|}{$\sigma_{\mathrm{e}} \leq$ allowable stress } \\
\hline
\end{tabular}

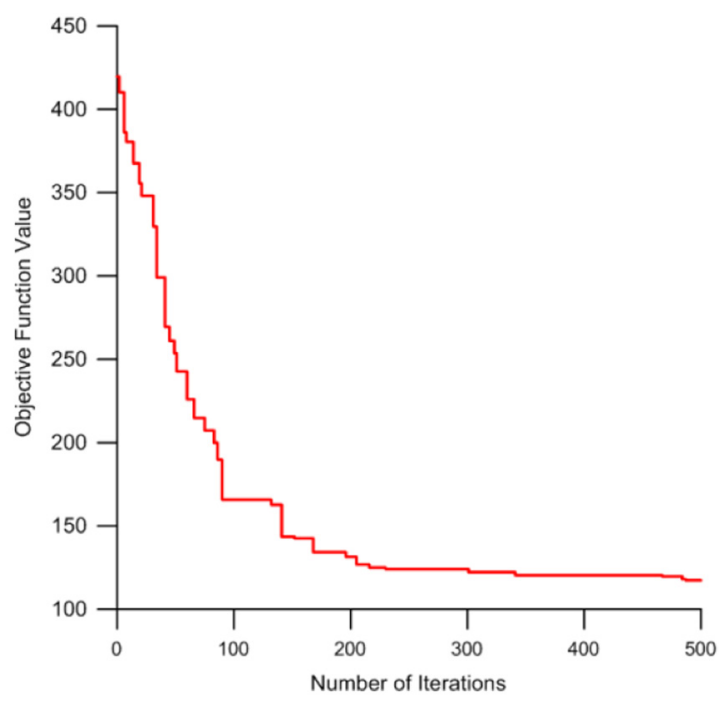

Fig. 10. Convergence history for the spatial 25-bar truss using iPSO

ple is declared in Table 7. The standard deviation value of the set of achieved solutions is $1.3908 \mathrm{lb}$. This shows that the solutions satisfactorily are spread out over the mean value of the solutions set.

\subsection{9-bar space truss tower}

The fourth test problem is the combined sizing/layout optimization of the 3D 39-bar truss tower shown in Figure 11. Problem specifications are listed in Table 8. Fixed nodes' coordinates and elements' connectivity are presented in Table 9. The top and bottom nodes have fixed position while middle nodes' coordinates are taken as design variables. The symmetry of structure is maintained during the optimization process. The population size and allowable number of iterations is set to 10 and 1000 , respectively.

The optimum design found by iPSO is demonstrated in Figure 12 while in Table 10 it is compared with those obtained from other methods. The solution obtained by iPSO is lighter than the cited references Wang et al. (2002) and Dede and Ayvaz (2015). This optimum design is attained at $725^{\text {th }}$ generation (i.e. after 7250 structural analyses). No further improvement is achieved through the remaining iterations. Table 10 provides the statistical information about the 30 independent runs of iPSO for this example.

The standard deviation $1.831 \mathrm{lb}$ indicates an acceptable distribution of the outcomes over the mean value of all independent runs. Since the buckling criterion is added as an extra constraint, the boundary condition of the prob- 
Table 6. Initial layout and member grouping for the spatial 25-bar truss problem

\begin{tabular}{|c|c|c|c|c|c|}
\hline $\begin{array}{c}\text { Joint } \\
\text { number }\end{array}$ & $\mathrm{x}$ (in) & $y($ in) & $\mathrm{z}$ (in) & Group & Member number (end joints number) \\
\hline 1 & $-95.25 \mathrm{~cm}(-37.5)$ & 0.0 & $508 \mathrm{~cm}(200)$ & $A_{1}$ & $1(1,2)$ \\
\hline 2 & $95.25 \mathrm{~cm}(37.5)$ & 0.0 & $508 \mathrm{~cm} \mathrm{(200)}$ & $A_{2}$ & $2(1,4), 3(2,3), 4(1,5), 5(2,6)$ \\
\hline 3 & $-95.25 \mathrm{~cm}(-37.5)$ & $95.25 \mathrm{~cm}(37.5)$ & $254 \mathrm{~cm}(100)$ & $A_{3}$ & $6(2,5), 7(2,4), 8(1,3), 9(1,6)$ \\
\hline 4 & $95.25 \mathrm{~cm}(37.5)$ & $95.25 \mathrm{~cm}(37.5)$ & $254 \mathrm{~cm}(100)$ & $A_{4}$ & $10(3,6), 11(4,5)$ \\
\hline 5 & $95.25 \mathrm{~cm}(37.5)$ & $-95.25 \mathrm{~cm}(-37.5)$ & $254 \mathrm{~cm}(100)$ & $A_{5}$ & $12(3,4), 13(5,6)$ \\
\hline 6 & $-95.25 \mathrm{~cm}(-37.5)$ & $-95.25 \mathrm{~cm}(-37.5)$ & $254 \mathrm{~cm}(100)$ & $A_{6}$ & $14(3,10), 15(6,7), 16(4,9), 17(5,8)$ \\
\hline 7 & $-254 \mathrm{~cm}(-100)$ & $254 \mathrm{~cm}(100)$ & 0.0 & $A_{7}$ & $18(3,8), 19(4,7), 20(6,9), 21(5,10)$ \\
\hline 8 & $254 \mathrm{~cm}(100)$ & $254 \mathrm{~cm}(100)$ & 0.0 & $A_{8}$ & $22(3,7), 23(4,8), 24(5,9), 25(6,10)$ \\
\hline 9 & $254 \mathrm{~cm}(100)$ & $-254 \mathrm{~cm}(-100)$ & 0.0 & & \\
\hline 10 & $-254 \mathrm{~cm}(-100)$ & $-254 \mathrm{~cm}(-100)$ & 0.0 & & \\
\hline
\end{tabular}

Table 7. Comparison of the iPSO optimization results with the literature for the spatial 25-bar truss problem

\begin{tabular}{|c|c|c|c|c|c|c|}
\hline Design variables & $\begin{array}{l}\text { Wu and Chow } \\
\text { (1995) GA }\end{array}$ & $\begin{array}{l}\text { Tang et al. } \\
\text { (2005) iGA }\end{array}$ & $\begin{array}{c}\text { Kaveh and Kalatjari } \\
\text { (2004) GA }\end{array}$ & $\begin{array}{l}\text { Rahami et al. } \\
\text { (2008) GA }\end{array}$ & $\begin{array}{l}\text { Gholizadeh } \\
\text { (2013) SCPSO }\end{array}$ & $\begin{array}{l}\text { This study } \\
\text { iPSO }\end{array}$ \\
\hline \multicolumn{7}{|c|}{ Sizing variables $\left(\mathrm{in}^{2}\right)$} \\
\hline$A_{1}$ & 0.1 & 0.1 & 0.1 & 0.1 & 0.1 & 0.1 \\
\hline$A_{2}$ & 0.2 & 0.1 & 0.1 & 0.1 & 0.1 & 0.1 \\
\hline$A_{3}$ & 1.1 & 1.1 & 1.1 & 1.1 & 1.0 & 1.0 \\
\hline$A_{4}$ & 0.2 & 0.1 & 0.1 & 0.1 & 0.1 & 0.1 \\
\hline$A_{5}$ & 0.3 & 0.1 & 0.1 & 0.1 & 0.1 & 0.1 \\
\hline$A_{6}$ & 0.1 & 0.2 & 0.1 & 0.1 & 0.1 & 0.1 \\
\hline$A_{7}$ & 0.2 & 0.2 & 0.1 & 0.2 & 0.1 & 0.1 \\
\hline$A_{8}$ & 0.9 & 0.7 & 1 & 0.8 & 0.9 & 0.9 \\
\hline \multicolumn{7}{|c|}{ Layout variables (in) } \\
\hline$X_{4}$ & 41.07 & 35.47 & 36.23 & 33.0487 & 36.9520 & 37.6 \\
\hline$Y_{4}$ & 53.47 & 60.37 & 58.56 & 53.5663 & 54.5786 & 54.46 \\
\hline$Z_{4}$ & 124.6 & 129.07 & 115.59 & 129.9092 & 129.9758 & 130 \\
\hline$X_{8}$ & 50.8 & 45.06 & 46.46 & 43.7826 & 51.7317 & 51.89 \\
\hline$Y_{8}$ & 131.48 & 137.04 & 127.95 & 136.8381 & 139.5316 & 139.55 \\
\hline \multicolumn{7}{|c|}{ Statistical results } \\
\hline Best weight (lb) & 136.2 & 124.94 & 124.0 & 120.1149 & 117.227 & 117.255 \\
\hline Worst weight (lb) & & & & & 132.672 & 121.969 \\
\hline Mean weight (lb) & & & & & 122.876 & 119.57 \\
\hline Std. deviation (lb) & & & & & 3.671 & 1.3908 \\
\hline OFEs & - & 6000 & - & 10000 & 4500 & 4870 \\
\hline
\end{tabular}


Table 8. Input data for the spatial 39-bar truss problem

\begin{tabular}{|c|c|c|c|}
\hline \multicolumn{4}{|c|}{ Material properties } \\
\hline Young's modulus & & $E=210 \mathrm{GPa}(30457.9249233 \mathrm{ksi})$ & \\
\hline Density & & $\rho=7800.2 \mathrm{~kg} / \mathrm{m}^{3}\left(0.2818 \mathrm{lb} / \mathrm{in}^{3}\right)$ & \\
\hline \multirow[t]{2}{*}{ Allowable stress } & & $\pm 240 \mathrm{MPa}( \pm 34.809048 \mathrm{ksi})$ & \\
\hline & & Design variables & \\
\hline \multirow[t]{4}{*}{ Sizing variables } & & $A_{i}=1,2,3,4,5$ & \\
\hline & & Layout variable & \\
\hline & & $Y_{12}, Z_{12}, Y_{13}, Z_{13}, Y_{14}, Z_{14}$ & \\
\hline & & Loading conditions & \\
\hline Node number & $\mathrm{x}$ & $\mathrm{y}$ & $\mathrm{z}$ \\
\hline 5 & & $10 \mathrm{kN}$ (2.2481 kips) & \\
\hline 10 & & 10 kN (2.2481 kips) & \\
\hline \multirow[t]{2}{*}{15} & & 10 kN (2.2481 kips) & \\
\hline & & Constraints & \\
\hline Displacement & $\mathrm{X}$ & Y & Z \\
\hline Node 13 & & $0.4 \mathrm{~cm}(0.1574 \mathrm{in})$ & \\
\hline Euler buckling & & $\sigma_{e b} \leq \frac{-K_{e} E A_{e}}{L_{e}^{2}}$ & \\
\hline Stress & & $\sigma_{\mathrm{e}} \leq$ allowable stress & \\
\hline
\end{tabular}

Table 9. Initial layout and member grouping for the spatial 39-bar truss problem

\begin{tabular}{cccccc}
\hline Joint number & $\mathrm{x}(\mathrm{m})$ & $\mathrm{y}(\mathrm{m})$ & $\mathrm{z}(\mathrm{m})$ & Group & (end joints number) \\
\hline 1 & & -0.5 & 0 & $A_{1}$ & $(1,2)(6,7)(11,12)$ \\
5 & -0.14 & 4 & $A_{2}$ & $(2,3)(7,8)(12,13)$ \\
6 & -0.5 & 0 & $A_{3}$ & $(3,4)(8,9)(13,14)$ \\
10 & -0.14 & 4 & $A_{4}$ & $(4,5)(9,10)(14,15)$ \\
11 & 0 & 1 & 0 & $A_{5}$ & Rest of the elements \\
15 & 0 & 0.28 & 4 & & \\
\hline
\end{tabular}

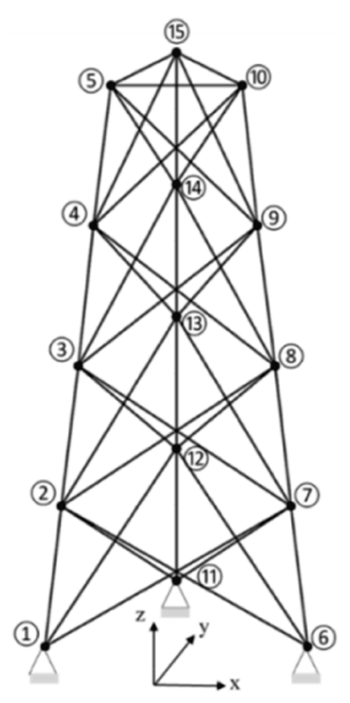

Fig. 11. Schematic of the spatial 39-bar truss tower

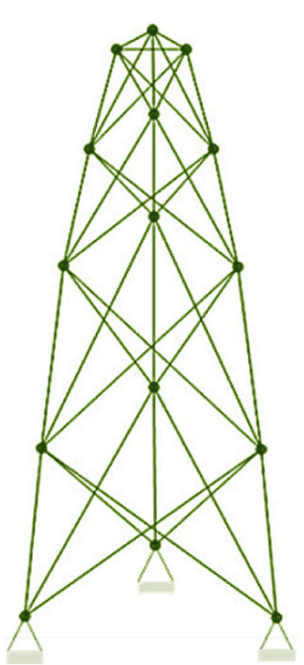

Fig. 12. Optimal layout for the spatial 39-bar truss problem 
Table 10. Comparison of the iPSO optimization results with the literature for the spatial 39-bar truss problem

\begin{tabular}{|c|c|c|c|}
\hline Design variables & Wang et al. (2002) FSD & Dede and Ayvaz (2015) TLBO & This study iPSO \\
\hline \multicolumn{4}{|c|}{ Sizing variables $\left(\mathrm{cm}^{2}\right)$} \\
\hline$A_{1}$ & 11.01 & 11.9650 & 12.08 \\
\hline$A_{2}$ & 8.63 & 11.1457 & 10.1 \\
\hline$A_{3}$ & 6.69 & 7.8762 & 6.64 \\
\hline$A_{4}$ & 4.11 & 2.7013 & 3.18 \\
\hline$A_{5}$ & 4.37 & 2.4058 & 1.72 \\
\hline \multicolumn{4}{|c|}{ Layout variables (m) } \\
\hline$Y_{12}$ & 0.805 & 0.8996 & 0.872 \\
\hline$Z_{12}$ & 1.186 & 1.3507 & 1.198 \\
\hline$Y_{13}$ & 0.654 & 0.6917 & 0.693 \\
\hline$Z_{13}$ & 2.204 & 2.3122 & 2.496 \\
\hline$Y_{14}$ & 0.466 & 0.4825 & 0.490 \\
\hline$Z_{14}$ & 3.092 & 3.3031 & 3.309 \\
\hline \multicolumn{4}{|c|}{ Statistical results } \\
\hline Best weight (kg) & 203.18 & 154.13 & 135.0552 \\
\hline Worst weight (kg) & & & 140.865 \\
\hline Mean weight (kg) & & & 138.58 \\
\hline Std. deviation (kg) & & & 1.831 \\
\hline OFEs & - & 7560 & 7250 \\
\hline
\end{tabular}

Table 11. Input data for the planar 47-bar truss problem

\begin{tabular}{|c|c|c|c|c|}
\hline & \multicolumn{4}{|c|}{ Material properties } \\
\hline Young's modulus & \multicolumn{4}{|c|}{$E=30 \mathrm{Msi}$} \\
\hline Density & \multicolumn{4}{|c|}{$\rho=0.30 \mathrm{lb} / \mathrm{in}^{3}$} \\
\hline \multirow[t]{2}{*}{ Allowable stress } & \multicolumn{4}{|c|}{$+20 \mathrm{ksi}$ and $-15 \mathrm{ksi}$ for members in tension and compression, respectively. } \\
\hline & \multicolumn{4}{|c|}{ Design variables } \\
\hline Sizing variables & \multicolumn{4}{|c|}{$A_{\mathrm{i}}=1,2, \ldots, 46,47$} \\
\hline Layout variables & \multirow{2}{*}{\multicolumn{4}{|c|}{$\begin{array}{c}X_{2}=-X_{1}, X_{4}=-X_{3}, Y_{4}=Y_{3}, X_{6}=-X_{5}, Y_{6}=Y_{5}, X_{8}=-X_{7}, Y_{8}=Y_{7}, X_{10}=-X_{9}, Y_{10}=Y_{9}, X_{12}=-X_{11}, \\
Y_{12}=Y_{11}, X_{14}=-X_{13}, Y_{14}=Y_{13}, X_{20}=-X_{19}, Y_{20}=Y_{19}, X_{21}=-X_{18}, Y_{21}=Y_{18} \\
\{0.1,0.2,0.3, \ldots, 4.8,4.9,5.0\} \mathrm{in}^{2}\end{array}$}} \\
\hline \multirow[t]{2}{*}{ Discrete area set } & & & & \\
\hline & \multicolumn{4}{|c|}{ Loading conditions } \\
\hline Load case & Node numbers & $\mathrm{x}$ & y & $\mathrm{z}$ \\
\hline 1 & 17 and 22 & 6.0 kips & -14.0 kips & 0 \\
\hline 2 & 17 & 6.0 kips & -14.0 kips & 0 \\
\hline \multirow[t]{2}{*}{3} & 22 & 6.0 kips & -14.0 kips & 0 \\
\hline & \multicolumn{4}{|c|}{ Constraints } \\
\hline \multicolumn{5}{|l|}{ Displacement } \\
\hline Euler buckling & \multicolumn{4}{|c|}{$3.96 E A / L^{2}$} \\
\hline Stress & \multicolumn{4}{|c|}{$\sigma_{\mathrm{e}} \leq$ allowable stress } \\
\hline
\end{tabular}




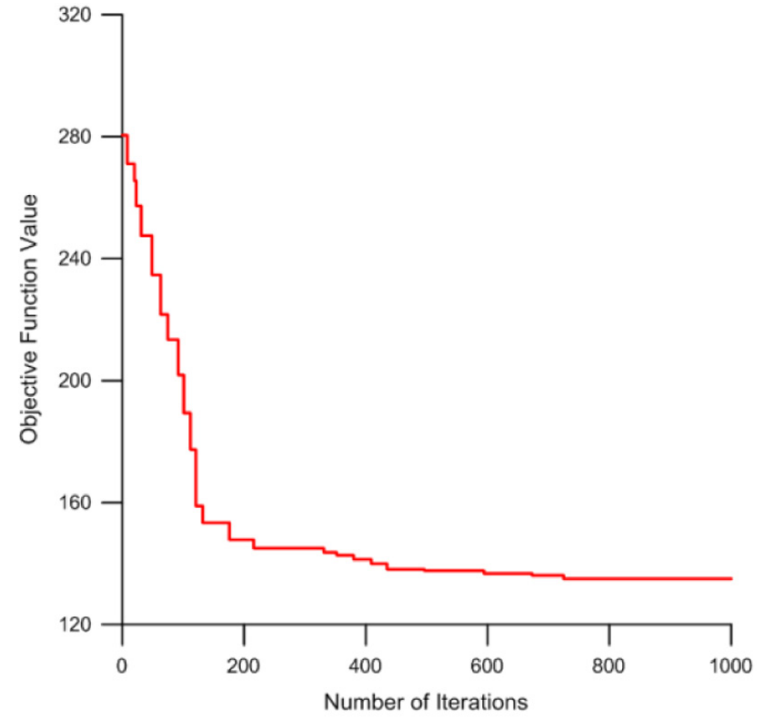

Fig. 13. Convergence history for the spatial 39-bar truss using iPSO

lem becomes more complex, thereupon the probability of existing more local optimum points in the search space is raised, and consequently the standard division of current example is higher than prior example. Figure 13 shows the convergence history of the 39-bar truss structure for iPSO.

\subsection{7-bar planar truss structure}

The last test problem is devoted to investigate the sizing and layout optimization of the planar 47-bar truss structure shown in Figure 14. The necessary data to model this problem are specified in Table 11. The population size and limit number of iterations are set as 40 and 600, respectively. Considering the symmetric about the y-axis, members of the 47-bar truss are collected into 27 independent groups as sizing variables in Table 12. Layout variables corresponding to the nodal coordinates are also presented in Table 11. Therefore, totally 44 design variables are taken into consideration during the optimization process of this test example. Furthermore, it can be seen from Table 11 that 47-bar truss structure is subject to the three independent loading conditions.

The optimum design found by iPSO is illustrated in Table 13 while for the sake of comparison the results obtained in other studies using other methods are also included. According to this table the present approach, iPSO, is competitive with all other results presented in Table 13 in finding optimum solution. The best weight for this case is found at $501^{\text {th }}$ iteration and any improvements are not occurred until the last iteration. The statistical information of 30 independent runs is also provided in Table 13. Standard deviation for Gholizadeh (2013) using sequential cellular particle swarm optimization (SCPSO) and this study using iPSO are 34.755 and $20.782 \mathrm{lb}$, respectively. The standard deviation on the optimized weight of the iPSO is comparatively lower than other cited methods, so there is
Table 12. Member grouping for the planar 47-bar truss problem

\begin{tabular}{cccc}
\hline Group & Member & Group & Member \\
\hline 1 & 1,3 & 16 & 28 \\
\hline 2 & 2,4 & 17 & 29,30 \\
\hline 3 & 5,6 & 18 & 31,32 \\
\hline 4 & 7 & 19 & 33 \\
\hline 5 & 8,9 & 20 & 34,35 \\
\hline 6 & 10 & 21 & 36,37 \\
\hline 7 & 11,12 & 22 & 38 \\
\hline 8 & 13,14 & 23 & 39,40 \\
\hline 9 & 15,16 & 24 & 41,42 \\
\hline 10 & 17,18 & 25 & 43 \\
\hline 11 & 19,20 & 26 & 44,45 \\
\hline 12 & 21,22 & 27 & 46,47 \\
\hline 13 & 23,24 & & \\
\hline 14 & 25,26 & & \\
\hline 15 & 27 & & \\
\hline
\end{tabular}

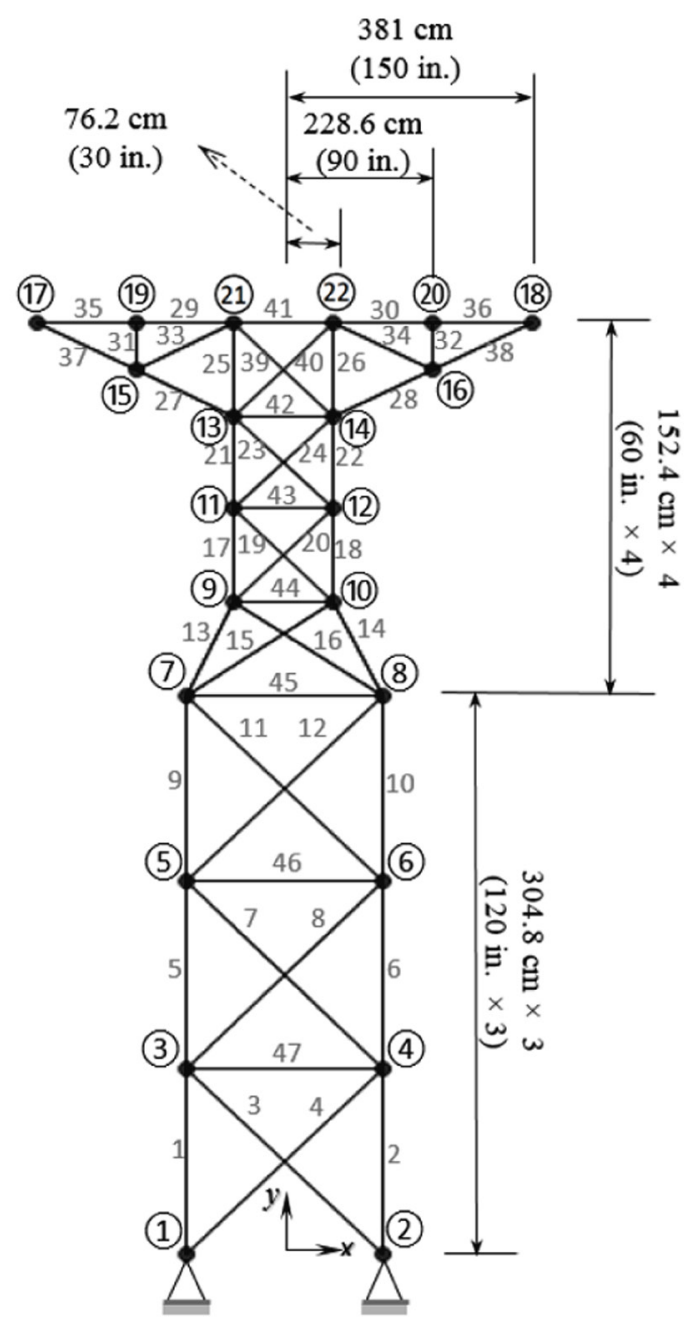

Fig. 14. Schematic of the planar 47-bar truss structure 
Table 13. Comparison of the iPSO optimization results with the literature for the planar 47-bar truss problem

\begin{tabular}{|c|c|c|c|c|c|c|}
\hline \multirow{2}{*}{ Design variables } & \multirow{2}{*}{$\begin{array}{c}\text { Hasancebi and } \\
\text { Erbatur (2001) iGA }\end{array}$} & \multirow{2}{*}{$\begin{array}{l}\text { Hasancebi and } \\
\text { Erbatur (2002) SA }\end{array}$} & \multicolumn{3}{|c|}{ Gholizadeh (2013) } & \multirow{2}{*}{$\begin{array}{c}\text { This study } \\
\text { iPSO }\end{array}$} \\
\hline & & & PSO & CPSO & SCPSO & \\
\hline$A_{1}$ & 2.5 & 2.5 & 2.8 & 2.6 & 2.5 & 2.5 \\
\hline$A_{2}$ & 2.2 & 2.5 & 2.7 & 2.5 & 2.5 & 2.5 \\
\hline$A_{3}$ & 0.7 & 0.8 & 0.8 & 0.7 & 0.8 & 0.8 \\
\hline$A_{4}$ & 0.1 & 0.1 & 1.1 & 0.3 & 0.1 & 0.1 \\
\hline$A_{5}$ & 1.3 & 0.7 & 0.8 & 1.2 & 0.7 & 0.7 \\
\hline$A_{6}$ & 1.3 & 1.3 & 1.3 & 1.1 & 1.4 & 1.4 \\
\hline$A_{7}$ & 1.8 & 1.8 & 1.8 & 1.6 & 1.7 & 1.7 \\
\hline$A_{8}$ & 0.5 & 0.7 & 0.9 & 0.8 & 0.8 & 0.8 \\
\hline$A_{9}$ & 0.8 & 0.9 & 1.2 & 1.1 & 0.9 & 0.9 \\
\hline$A_{10}$ & 1.2 & 1.2 & 1.4 & 1.3 & 1.3 & 1.3 \\
\hline$A_{11}$ & 0.4 & 0.4 & 0.3 & 0.3 & 0.3 & 0.3 \\
\hline$A_{12}$ & 1.2 & 1.3 & 1.4 & 0.8 & 0.9 & 0.9 \\
\hline$A_{13}$ & 0.9 & 0.9 & 1.1 & 1.0 & 1.0 & 1.0 \\
\hline$A_{14}$ & 1.0 & 0.9 & 1.2 & 1.0 & 1.1 & 1.1 \\
\hline$A_{15}$ & 3.6 & 0.7 & 1.6 & 0.9 & 5.0 & 0.9 \\
\hline$A_{16}$ & 0.1 & 0.1 & 1.0 & 0.1 & 0.1 & 0.1 \\
\hline$A_{17}$ & 2.4 & 2.5 & 2.8 & 2.7 & 2.5 & 2.5 \\
\hline$A_{18}$ & 1.1 & 1.0 & 0.8 & 0.9 & 1.0 & 1.0 \\
\hline$A_{19}$ & 0.1 & 0.1 & 0.1 & 0.1 & 0.1 & 0.1 \\
\hline$A_{20}$ & 2.7 & 2.9 & 3.0 & 3.0 & 2.8 & 2.8 \\
\hline$A_{21}$ & 0.8 & 0.8 & 0.9 & 1.0 & 0.9 & 0.9 \\
\hline$A_{22}$ & 0.1 & 0.1 & 0.1 & 0.2 & 0.1 & 0.1 \\
\hline$A_{23}$ & 2.8 & 3.0 & 3.3 & 3.3 & 3.0 & 3.0 \\
\hline$A_{24}$ & 1.3 & 1.2 & 0.9 & 0.9 & 1.0 & 1.0 \\
\hline$A_{25}$ & 0.2 & 0.1 & 0.1 & 0.1 & 0.1 & 0.1 \\
\hline$A_{26}$ & 3.0 & 3.2 & 3.3 & 3.3 & 3.2 & 3.2 \\
\hline$A_{27}$ & 1.2 & 1.1 & 1.2 & 1.1 & 1.2 & 1.2 \\
\hline \multicolumn{7}{|c|}{ Layout variables (in) } \\
\hline$X_{2}$ & 114.0 & 104.0 & 98.8628 & 99.363 & 101.3393 & 101.2077 \\
\hline$X_{4}$ & 97.0 & 87.0 & 78.6595 & 83.4439 & 85.9111 & 85.8555 \\
\hline$Y_{4}$ & 125.0 & 128.0 & 146.7331 & 126.3845 & 135.9645 & 135.9679 \\
\hline$X_{6}$ & 76.0 & 70.0 & 66.5231 & 69.5148 & 74.7969 & 74.9087 \\
\hline$Y_{6}$ & 261.0 & 259.0 & 239.0901 & 218.2013 & 237.7447 & 238.0442 \\
\hline$X_{8}$ & 69.0 & 62.0 & 55.6936 & 58.0004 & 64.3115 & 64.1206 \\
\hline$Y_{8}$ & 316.0 & 326.0 & 327.7882 & 322.2272 & 321.3416 & 321.5037 \\
\hline$X_{10}$ & 56.0 & 53.0 & 48.8641 & 51.4015 & 53.3345 & 53.3481 \\
\hline$Y_{10}$ & 414.0 & 412.0 & 398.6775 & 401.5626 & 414.3025 & 413.7265 \\
\hline$X_{12}$ & 50.0 & 47.0 & 43.14 & 46.8605 & 46.0277 & 46.2881 \\
\hline$Y_{12}$ & 463.0 & 486.0 & 464.7831 & 458.3021 & 489.9216 & 487.9695 \\
\hline$X_{14}$ & 54.0 & 45.0 & 37.8993 & 46.8885 & 41.8353 & 41.8603 \\
\hline$Y_{14}$ & 524.0 & 504.0 & 511.045 & 527.8575 & 522.4161 & 522.8897 \\
\hline$X_{20}$ & 1.0 & 2.0 & 18.2341 & 16.2354 & 1.0005 & 0.9892 \\
\hline$Y_{20}$ & 587.0 & 584.0 & 594.071 & 610.8496 & 598.3905 & 598.3959 \\
\hline$X_{21}$ & 99.0 & 89.0 & 90.9369 & 98.3239 & 97.8696 & 97.8656 \\
\hline$Y_{21}$ & 631.0 & 637.0 & 621.3943 & 624.958 & 624.055 & 624.0605 \\
\hline \multicolumn{7}{|c|}{ Statistical results } \\
\hline Best weight (lb) & 1925.79 & 1871.70 & 1975.84 & 1908.83 & 1864.10 & 1861.429 \\
\hline Worst weight (lb) & & & & & 2007.563 & 1908.991 \\
\hline Mean weight (lb) & & & & & 1894.056 & 1873.011 \\
\hline Std. deviation (lb) & & & & & 34.755 & 20.782 \\
\hline OFEs & 100000 & N/A & 25000 & 25000 & 25000 & 20040 \\
\hline
\end{tabular}




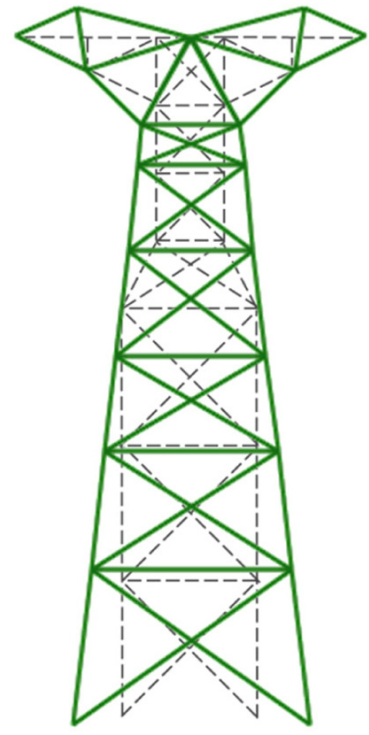

Fig. 15. Optimal layout for the planar 47-bar truss problem

relatively less dispersion in the obtained solutions. Considering the previous problems, this problem is a largescale optimization problem, and based on the numerical results reported in Table 13, it can be stated that the proposed iPSO algorithm can find the best optimal solution among the cited methods for the this problem. Figure 15 shows the optimal design found for this problem. Besides, Figure 16 demonstrates the convergence history of the 47-bar truss structure using iPSO.

\section{Discussion}

In this study the concept of weighted particle is utilized for both position updating and constraints handling features of the proposed algorithm. The new approach is called improved Fly-back technique. In this recent approach the search space is divided into two different categories and so the problem domain is examined more accurately. Furthermore, by incorporating the weighted particle into constraints handling process the affirmative data stored in this particle is used to handle the constraints. Since the weighted particle is the weighted average of all particles on the swarm, sharing its components with the violated particles can improve the exploitation feature of the algorithm. Especially, weighted particle lies closer, but not at same position, to the $\mathbf{X}^{G}$. On the other hand the weighted particle can share experience of all existing particles with the particle that violates the numeric boundary condition of the search space. This means all particles can interact with each other through the weighted particle.

Improved Fly-back mechanism plays two important roles: first, it emphasizes the role of the weighted particle as the guidance point for other particles (i.e. enhancing the exploitation) and second, it gives an opportunity to access the components stored in the weighted particle (i.e. enhancing the exploration). In this respect, Figure 17 compares the performance of the standard and improved

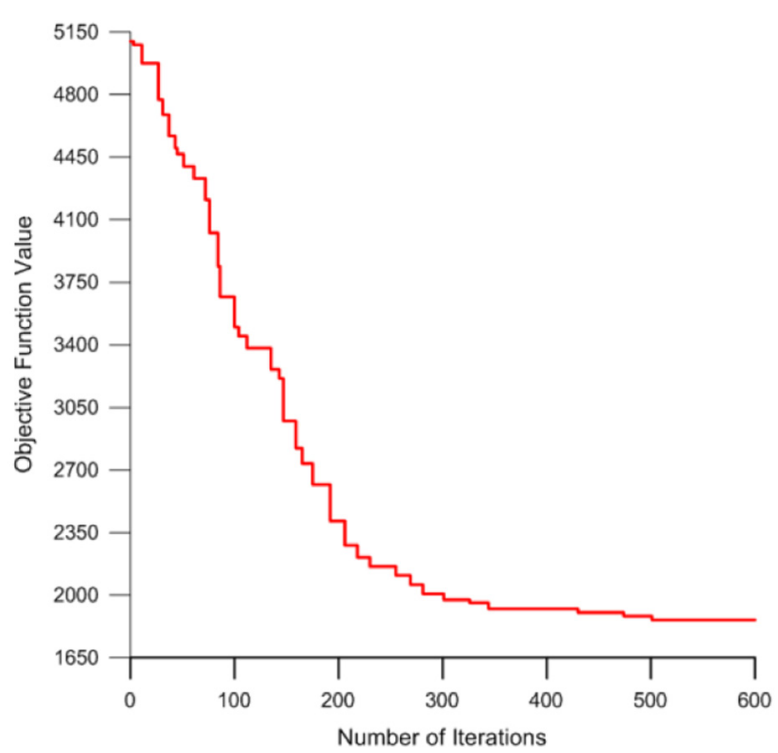

Fig. 16. Convergence history for the planar 47-bar truss using iPSO

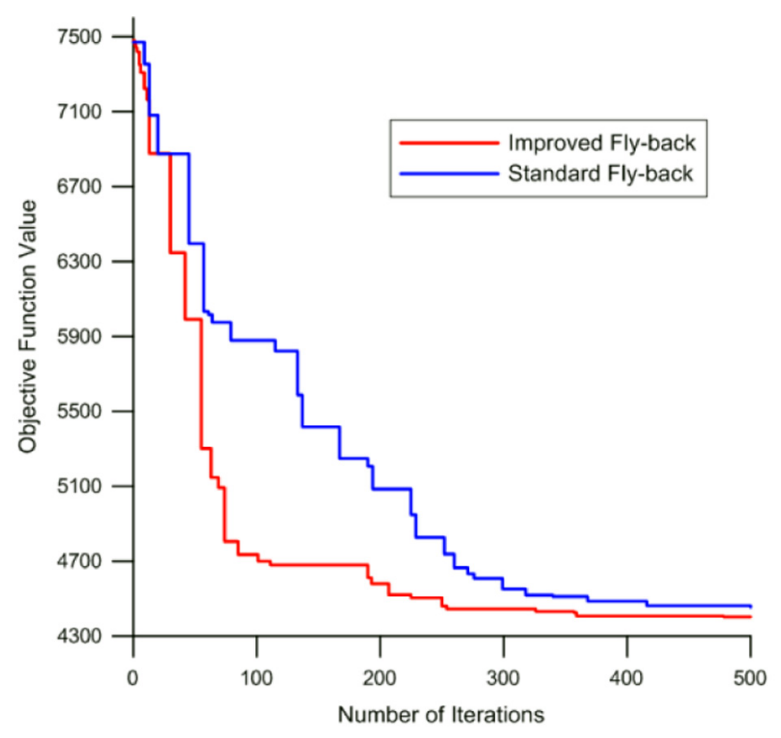

Fig. 17. Comparison between the standard and improved flyback mechanism on 18-bar truss problem

Fly-back methods on the optimization of 18-bar truss structure. As can be seen from this figure, the convergence rate and final outcome of improved Fly-back technique are good than its old form. It is notable that, since the condition is qualitatively identical for all other examples, the diagram is plotted just for 18-bar truss problem to prevent any unnecessary congestion.

\section{Conclusions}

Integrated particle swarm optimization (iPSO) improves the standard PSO's search capability by implementing the concept of weighted particle and improved Fly-back approach. The enhancement is mostly in order to avoiding the algorithm from premature convergence into lo- 
cal optima(s). Furthermore, unlike the classical penalty function approach, the improved Fly-back strategy enables iPSO to consistently acquire feasible solutions without any violations in the boundary conditions. The proposed algorithm was tested on five well known weight minimization problems of truss structures. All of them include sizing and layout variables and the last one is the slightly higher scale problem consisting of totally 44 sizing and layout variables. The statistical data for each example is provided and based on acquired outcomes the iPSO shows adequate robustness and the iPSO can be considered as an efficient algorithm for solving combined sizing/layout optimization problems of truss structures.

\section{References}

Achtziger, W. 2007. On simultaneous optimization of truss geometry and topology, Structural Multidisciplinary Optimization 33(4): 285-305.

https://doi.org/10.1007/s00158-006-0092-0

Artar, M. 2016. Optimum design of braced steel frames via teaching learning based optimization, Steel and Composite Structures 22(4): 733-744. https://doi.org/10.12989/scs.2016.22.4.733

Aydın, Z.; Çakır, E. 2015. Cost minimization of prestressed steel trusses considering shape and size variables, Steel and Composite Structures 19(1): 43-58. https://doi.org/10.12989/scs.2015.19.1.043

Bekdaş, G.; Nigdeli, S. M.; Yang, X. S. 2015. Sizing optimization of truss structures using flower pollination algorithm, Applied Soft Computing 37: 322-331. https://doi.org/10.1016/j.asoc.2015.08.037

Deb, K.; Gulati, S. 2001. Design of truss-structures for minimum weight using genetic algorithms, Finite Elements in Analysis and Design 37: 447-465. https://doi.org/10.1016/S0168-874X(00)00057-3

Dede, T.; Ayvaz, Y. 2015. Combined size and shape optimization of structures with a new meta-heuristic algorithm, $A p$ plied Soft Computing 28: 250-258. https://doi.org/10.1016/j.asoc.2014.12.007

Gholizadeh, S. 2013. Layout optimization of truss structures by hybridizing cellular automata and particle swarm optimization, Computers and Structures 125: 86-99. https://doi.org/10.1016/j.compstruc.2013.04.024

Gholizadeh, S. 2015. Performance-based optimum seismic design of steel structures by a modified firefly algorithm and a new neural network, Advances in Engineering Software 81: 50-65. https://doi.org/10.1016/j.advengsoft.2014.11.003

Gholizadeh, S.; Fattahi, F. 2014. Design optimization of tall steel buildings by a modified particle swarm algorithm, The Structural Design of Tall and Special Buildings 23: 285-301. https://doi.org/10.1002/tal.1042

Gholizadeh, S.; Poorhoseini, H. 2015. Optimum design of steel frame structures by a modified dolphin echolocation algorithm, Structural Engineering and Mechanics 55(3): 535-554. https://doi.org/10.12989/sem.2015.55.3.535

Hasançebi, O.; Erbatur, F. 2001. Layout optimization of trusses using improved GA methodologies, Acta Mechanica 146: 87-107. https://doi.org/10.1007/BF01178797

Hasançebi, O.; Erbatur, F. 2002. On efficient use of simulated annealing in complex structural optimization problems, Acta Mechanica 157: 27-50. https://doi.org/10.1007/BF01182153

Hasançebi, O.; Erdal, F.; Saka, M. P. 2009. Adaptive harmony search method for structural optimization, Journal of Structural Engineering 136(4): 419-431. https://doi.org/10.1061/(ASCE)ST.1943-541X.0000128
He, S.; Prempain, E.; Wu, Q.H. 2004. An improved particle swarm optimizer for mechanical design optimization problems, Engineering Optimization 36: 585-605. https://doi.org/10.1080/03052150410001704854

Hwang, S. F.; He, R. S. 2006. A hybrid real-parameter genetic algorithm for function optimization, Advanced Engineering Informatics 20(1): 7-21. https://doi.org/10.1016/j.aei.2005.09.001

Kaveh, A. 2004. Structural mechanics: Graph and matrix methods. Research Studies Press.

Kaveh, A. 2006. Optimal structural analysis. John Wiley \& Sons, Ltd. https://doi.org/10.1002/9780470033326

Kaveh, A.; Kalatjari, V. 2004. Size, geometry optimization of trusses by the force method and genetic algorithm, Journal of Applied Mathematics and Mechanics 84(5): 347-357. https://doi.org/10.1002/zamm.200310106

Kaveh, A.; Shokohi, F. 2015. Optimum design of laterally-supported castellated beams using $\mathrm{CBO}$ algorithm, Steel and Composite Structures 18(2): 305-324. https://doi.org/10.12989/scs.2015.18.2.305

Kennedy, J.; Eberhart, R. C. 2001. Swarm intelligence. Morgan Kaufmann Publishers.

Lee, Y.; Filliben, J. J.; Micheals, R. J.; Phillips, P. J. 2013. Sensitivity analysis for biometric systems: a methodology based on orthogonal experiment designs, Computer Vision and Image Understanding 117(5): 532-550. https://doi.org/10.1016/j.cviu.2013.01.003

Lee, K. S.; Geem, Z. W. 2005. A new meta-heuristic algorithm for continuous engineering optimization: harmony search theory and practice, Computer Methods in Applied Mechanics and Engineering 194(36-38): 3902-3933. https://doi.org/10.1016/j.cma.2004.09.007

Li, L. J.; Huang, Z. B.; Liu, F. 2009. A heuristic particle swarm optimization method for truss structures with discrete variables, Computers and Structures 87(7-8): 435-443. https://doi.org/10.1016/j.compstruc.2009.01.004

Li, N.; Wang, W.; Hsu, C.; Chang, W.; Chou, H.; Chang, J. 2014. Enhanced particle swarm optimizer incorporating a weighted particle, Neurocomputing 124: 218-227. https://doi.org/10.1016/j.neucom.2013.07.005

Miguel, L. F. F.; Lopez, R. H.; Miguel, L. F F. 2013. Multimodal size, shape, and topology optimization of truss structures using the Firefly algorithm, Advances in Engineering Software 56: 23-37. https://doi.org/10.1016/j.advengsoft.2012.11.006

Miguel, L. F. F.; Miguel, L. F. F. 2012. Shape and size optimization of truss structure considering dynamic constraints through modern metaheuristic algorithms, Expert Systems with Applications 39(10): 9458-9467. https://doi.org/10.1016/j.eswa.2012.02.113

Mortazavi, A.; Toğan, V. 2016. Simultaneous size, shape, and topology optimization of truss structures using integrated particle swarm optimizer, Structural Multidisciplinary Optimization 54: 715-736.

https://doi.org/10.1007/s00158-016-1449-7

Mortazavi, A.; Toğan, V. 2017. Sizing and layout design of truss structures under dynamic and static constraints with an integrated particle swarm optimization algorithm, Applied Soft Computing 51: 239-252. https://doi.org/10.1016/j.asoc.2016.11.032

Mortazavi, A.; Toğan, V.; Nuhoğlu, A. 2017. An integrated particle swarm optimizer for optimization of truss structures with discrete variables, Structural Engineering and Mechanics 61(3): 359-370. https://doi.org/10.12989/sem.2017.61.3.359

Phan, D. T.; Lim, J. B. P.; Tanyimboh, T. T.; Sha, W. 2013. An efficient genetic algorithm for the design optimization of cold-formed steel portal frame buildings, Steel and Composite Structures 15(5): 519-538.

https://doi.org/10.12989/scs.2013.15.5.519 
Rahami, H.; Kaveh, A.; Gholipour, Y. 2008. Sizing, geometry and topology optimization of trusses via force method and genetic algorithm, Engineering Structures 30(9): 2360-2369. https://doi.org/10.1016/j.engstruct.2008.01.012

Silih, S.; Kravanja, S.; Premrov, M. 2010. Shape and discrete sizing optimization of timber trusses by considering of joint flexibility, Advances in Engineering Software 41(2): 286-294. https://doi.org/10.1016/j.advengsoft.2009.07.002

Tang, W.; Tong, L.; Gu, Y. 2005. Improved genetic algorithm for design optimization of truss structures with sizing, shape and topology variables, International Journal of Numerical Methods in Engineering 62(13): 1737-1762. https://doi.org/10.1002/nme.1244
Torii, A. J.; Lopez, R. H.; Luersen, M. 2011. A local-restart coupled strategy for simultaneous sizing and geometry truss optimization, Latin American Journal of Solids and Structures 8(3): 335-349. https://doi.org/10.1590/S1679-78252011000300008

Van den Bergh, F.; Engelbrecht, A. 2003. Using neighborhood with the guaranteed convergence PSO, in IEEE Swarm Intelligence Symposium, USA, 235-242.

Wang, D.; Zhang, W. H.; Jiang, J.S. 2002. Combined shape and sizing optimization of truss structures, Computational Mechanics 29(4): 307-312. https://doi.org/10.1007/s00466-002-0343-x

Wu, S. J.; Chow, P. T. 1995. Integrated discrete and configuration optimization of trusses using genetic algorithms, Computers and Structures 55(4): 695-702. https://doi.org/10.1016/0045-7949(94)00426-4

Vedat TOĞAN. Received the BSc and MSc degrees in 2000 and 2004 from the Department of Civil Engineering from Karadeniz Technical University, Turkey respectively. He received his PhD degree from the same university in 2009. He is working as an Associate Professor at Civil Engineering Department of Karadeniz Technical University. His research interest includes meta-heuristic algorithms, optimization, reliability analysis, and construction managements.

Ali MORTAZAVI. Received the BSc and MSc degrees in 2007 and 2010 from the Department of Civil Engineering from Azad University, Iran respectively. He received his $\mathrm{PhD}$ degree from the Department of Civil Engineering from Ege University in May, 2017. His research interest includes finite element method, optimization, computer programming, and structural behaviors.

Ayhan NUHOĞLU. Received the BSc and MSc degrees in 1987 and 1990 from the Department of Civil Engineering from Karadeniz Technical University and Anadolu University Turkey respectively. He received his PhD degree from Anadolu University in 1997. He has been working as an Assistant Professor at Civil Engineering Department of Ege University since 1998. His research interest includes structural engineering, and structural behaviors. 